УДК 94(5)

DOI $10.17223 / 19988613 / 34 / 16$

\title{
Е.Ю. Тройнина
}

\section{ЭВОЛЮЦИЯ НАУЧНО-ТЕХНОЛОГИЧЕСКОЙ ПОЛИТИКИ ПРАВИТЕЛЬСТВА ТАЙВАНЯ В 1970-2000-е гг.: ГРУППЫ ВЛИЯНИЯ}

\begin{abstract}
Анализируется эволюция механизма принятия решений в области науки и технологий правительства Тайваня с 1970-х по 2000-е гг. с точки зрения воздействия различных групп влияния на этот процесс. Рассматриваются особенности разработки научно-технологической политики в условиях авторитарного и демократического режимов. На примере одной из приоритетных наукоемких отраслей - биотехнологий - рассмотрена сложная структура групп влияния, участвующих в формировании правительственной политики в данной области.

Ключевые слова: Тайвань; наука и технологии; группы влияния.
\end{abstract}

В основе динамичного развития науки и технологий на Тайване, начавшегося в 1970-х гг., лежит целый комплекс факторов, таких как отсутствие природных ресурсов, богатое наследие японских колонизаторов в области образования, наличие соседствующих странконкурентов с избыточными и дешевыми трудовыми ресурсами. Однако основной движущей силой научнотехнологического развития на начальном этапе стала государственная политика правительства Тайваня.

До начала процесса демократизации, инициированного президентом Цзян Цзинго в середине 1980-х гг. и активно проводимого президентом Ли Дэнхуэем с 1988 г., на Тайване сохранялся авторитарный режим правления партии Гоминьдан. При этом курс экономического развития формировался технократами - научно-техническими специалистами, которые занимали высокие должности в административном аппарате правительства и были уполномочены принимать решения, которые определяли государственную политику.

К наиболее ярким представителям технократической группы, которая определяла экономическую политику Тайваня, относятся Янь Цзягань (1904-1993), Ли Годин (1910-2001), Сунь Юньсюань (1913-2006), Юй Гохуа (1914-2000), Ян Цзицзэн (1898-1993) и др. Совокупность следующих сходных характеристик позволяет объединить этих государственных деятелей в одну группу [1. С. 186]:

- западное образование (технического или естественнонаучного профиля), вследствие чего они придерживались западных экономических концепций;

- наличие опыта работы на государственной службе в период, когда правительство Гоминьдана располагалось на территории континентального Китая (до 1949 г.);

- наличие опыта руководства экономикой военного времени, а также послевоенного экономического восстановления;

- представители технократов на Тайване являлись сторонниками экономического национализма, экономической стабильности, фискального и монетарного консерватизма.

Основным подходом технократов стал научный прагматизм, с точки зрения модели развития приоритет отдавался государственному капитализму, т.е. частной экономике с руководящей ролью государства, они пользовались доверием президентов Чан Кайши и Цзян Цзинго, а их инициативы находили поддержку в правящих кругах США [2. С. 102]. В 1970-1980-х гг. технократы обладали достаточно высокой степенью независимости в сфере принятия финансовоэкономических решений, при этом они не претендовали на политическую власть и тем самым обеспечили себе поддержку руководства Тайваня.

Группы влияния оказывали слабое давление на принятие технократами решений как в области экономики, так и в сфере науки и технологий. Поэтому с точки зрения экономической политики правящий режим на Тайване до конца 1980-х гг. можно назвать технократическим. Между тайваньскими технократами и местными группами влияния существовало естественное препятствие, так как тайваньские технократы были выходцами из континентального Китая, а традиционные группы влияния (ассоциации предприятий и собственников земли) имели тайваньское происхождение [3. C. 328].

Технократы занимали ведущие посты в правительстве Гоминьдана (в министерстве финансов и министерстве экономики), входили в состав Комитета по международному экономическому сотрудничеству и развитию при Исполнительном Юане (был учрежден в сентябре 1963 г. и заменил собой Комитет по вопросам американской помощи), который занимался экономическим планированием, вопросами привлечения иностранных инвестиций и заимствования зарубежных технологий. В области развития науки и технологий членами комитета были одобрены программы международных стажировок тайваньских специалистов, приглашались зарубежные специалисты для передачи исследовательского опыта. Технократы в различных комитетах министерства экономики стремились к максимально эффективному использованию экономической поддержки со стороны США, и в то же время их основной целью была экономическая самостоятельность Тайваня [2. С. 98-99].

В 1969 г. состоялся 10-й съезд партии, на котором Чан Кайши провозгласил необходимость проведения 
политических реформ, а также сделал акцент на критической важности кадров с точки зрения политического и экономического управления. В рамках заявленного курса в кадровой политике на министерские должности были назначены представители технократической группы [3. С. 327]:

- Ли Годин (1969-1976 гг. - министр финансов);

- Сунь Юньсюань (1969-1978 гг. - министр экономики);

- Юй Гохуа (1969-1984 гг. - глава Центрального банка Тайваня);

- Янь Цзягань (1966-1975 гг. - вице-президент).

После смерти Чан Кайши в 1975 г. и прихода к власти его сына Цзян Цзинго, который был избран президентом Тайваня на Национальной Ассамблее в 1978 г., положение технократов-чиновников стало менее устойчивым. Несмотря на то что Цзян Цзинго продолжал опираться на технократов, его отношение к ним было более настороженным, но, тем не менее, достаточно доверительным, учитывая то, что технократы, в частности Ли Годин, пользовались поддержкой США.

В ноябре 1976 г. была создана группа по вопросам прикладных научно-технологических исследований под руководством одного из наиболее ярких представителей тайваньских технократов Ли Година. В январе 1978 г. была проведена первая общетайваньская научно-технологическая конференция, участие в которой принимали чиновники, представители бизнеса и научных кругов с целью обсуждения основных направлений научно-технологического развития. На этой конференции Ли Годин выдвинул план создания научнотехнологического парка по аналогии с американской «Силиконовой долиной». Сунь Юньсюань также активно выступал за создание научного парка Синьчжу (за несколько лет до этого он также активно способствовал продвижению идеи создания Института индустриально-технологических исследований, основанного в 1973 г. [4. С. 14]). Исполнительный Юань поддержал план Ли, а также создал Консультативную группу по вопросам науки и технологий, в которую были приглашены тайваньские и иностранные эксперты. В результате с 1982 г. началось активное развитие передовых технологий в области энергетики, создания новых материалов, информатики, автоматизации, оптоволоконной промышленности, биотехнологий, медицины.

Технократическая система обеспечивала государственный аппарат чиновниками, которые имеют специальные знания и одновременно являются принимающими решения лицами. Так как технократы в своей деятельности опирались на американскую экономическую теорию и, ввиду своего образования, были более восприимчивы к американским идеям, они фактически стали проводником американского влияния, которое отразилось на концепции экономического управления и развития. Технократический аппарат государственного управления способствовал проникновению американских ценностей, взглядов и опыта на Тайвань
[2. С. 103]. Кроме того, технократы, которые получили образование в США или европейских странах, сохранили достаточно тесные связи с научными, предпринимательскими, финансово-экономическими и политическими кругами соответствующих государств. Эти связи повлияли на склонность тайваньских технократов к интернационализации, обеспечили необходимую техническую и кадровую поддержку в процессе экономической модернизации Тайваня.

В результате осуществления технократами научнотехнологической политики к 1988 г. был создан фундамент для развития инновационной системы Тайваня: система высшего образования, основные исследовательские институты и лаборатории, технологические корпорации. Расходы на исследования и разработки в 1988 г. составили 1,24\% от ВВП [5. С. 20], из них $56,5 \%$ были получены из государственных источников, $43,5 \%$ - из частного сектора [6. С. 166].

В то же время при технократическом режиме проявился следующий ряд проблем:

- Ориентация на крупные корпорации с государственным капиталом привела к тому, что малые и средние предприятия выпали из поля зрения технократов с точки зрения научно-технологического развития [7. С. 93]. Этот разрыв усиливался китайским происхождением технократов и тайваньским происхождением предпринимателей.

- Социальное напряжение, связанное с недостатком легитимности полномочий технократов, и политическая неопределенность в вопросах передачи власти, которые обострились в середине 1980-х гг. [8. С. 283-284].

- Координация инновационной системы в течение технократического периода носила характер почти ручного управления, которое само по себе является наиболее эффективным на начальных стадиях развития или в периоды кризиса. Появление и эволюция научнотехнологической системы (на фоне трансформации политической системы) потребовали нового - системного - метода управления, при котором все элементы системы интегрируются таким образом, чтобы каждый из них работал максимально эффективно для достижения общей системной цели.

Демократизация режима, начавшаяся в середине 1980-х гг., поставила перед обществом вопрос о том, чьи интересы защищает технократический режим: интересы народа или свои собственные, т.е. вопрос о доверии народа по отношению к существующей системе экономического управления. После начала процесса демократизации, усиления групп влияния и ухода со своих постов «старой технократической гвардии» уровень знаний и квалификации чиновников стал снижаться, и после прихода к власти Демократической прогрессивной партии (ДПП) авторитет технократов как правящей прослойки на Тайване был подорван [9], а отклик высших государственных деятелей в отношении предложений технократической группы значительно ослабел. 
Тем не менее к этому времени экономика Тайваня и составляющие ее элементы были готовы к повышению самостоятельности системы, а бизнес уже начал тяготиться государственной опекой. Данные трансформации привели к значительному усложнению процесса разработки экономического курса. В регулярно принимаемых планах экономического развития (Десятилетний план национального развития на 1980 1989 гг., Шестилетний план национального развития на 1991-1996 гг., Национальный план развития «Вызов-2008», 2002-2008 гг.) ставятся традиционные цели повышения конкурентоспособности тайваньской экономики за счет создания и развития инноваций. Однако в демократических условиях государственная экономическая политика представляет собой распределение на конкурентных началах имеющихся ресурсов между теми или иными правительственными департаментами, которые, в свою очередь, распределяют эти средства среди организаций, чьи интересы они представляют в правительстве.

Вовлеченность различных институтов и групп влияния в процесс принятия правительством решений хорошо прослеживается на примере одной из наиболее приоритетных инновационных отраслей экономики Тайваня - биотехнологий. В данной отрасли в процесс принятия решений вовлечены следующие институты и группы:

1. Институты исполнительной власти: Академия Синика (аналог Российской Академии Наук), Национальный совет по науке (фактическое Министерство науки), Министерство экономики, Министерство здравоохранения, Министерство образования и Совет по сельскому хозяйству (министерство). Между этими учреждениями идет соперничество за ресурсы, которые будут распределены государством на развитие биотехнологий, практически отсутствуют механизмы институциональной координации.

2. Институты законодательной власти: Законодательный Юань - высший законодательный орган Тайваня - является ареной политического противостояния «зеленой» коалиции под эгидой ДПП и «голубой» коалиции, возглавляемой партией Гоминьдан. По мнению тайваньского исследователя Чао Чэня, детальная разработка законопроектов по развитию биотехнологий нередко уходит на второй план, в связи с чем законодательные акты принимаются недоработанными [10. C. 10].

3. Неправительственные внутренние группы влияния включают:

a) местные малые и средние предприятия, работающие в области биотехнологий. Обычно эта группа представлена старт-апами, чей экономический вес недостаточно велик, чтобы оказывать серьезное влияние на государство в области принятия соответствующих решений. В то же время преобладание малых и средних предприятий в тайваньской экономике в целом (их доля в 2000-е гг. в среднем составляла 97\% от общего числа предприятий [11. С. 15]) обусловило тот факт, что при принятии решений в области экономического и научно-технологического развития так или иначе учитываются интересы малого и среднего бизнеса [12. C. 35];

б) государственные исследовательские институты в лице академиков, методы влияния которых включают взаимодействие с государственными служащими, предоставление экспертного мнения, участие в формальных и неформальных встречах, участие в правительственных программах и проектах. Однако их мнение не является решающим, а носит рекомендательный характер. В случае, если рекомендации ученых и экспертов противоречат политическим интересам лиц, принимающих решения, приоритетными являются политические интересы [10. С. 12], тогда как технократическая модель отдавала предпочтение профессиональной точке зрения и научному подходу формирования государственной политики;

в) университеты, влияние которых также осуществляется в форме личного участия отдельных ученых.

Данные группы влияния характеризуются разобщенностью, отсутствием артикуляции общих требований и координации совместных действий, вследствие этого совокупная эффективность влияния оказывается низкой и сводится к воздействию через личные знакомства и связи.

Несмотря на то что основные политические силы (Гоминьдан и ДПП) в целом придерживаются одного мнения касательно направления развития биотехнологий (модернизация сельского хозяйства, медицины, медицинской техники и т.д.), представители данных направлений в правительстве стараются представить свою зону ответственности как наиболее важную, тем самым создавая конфликт интересов: Министерство здравоохранения акцентирует внимание на эффективности здравоохранения, необходимости принятия строгих стандартов утверждения медицинских препаратов, Министерство экономики воспринимает эти меры в качестве препятствий для привлечения частных инвестиций. Совет по сельскому хозяйству, в свою очередь, стремится к получению субсидий для развития сельскохозяйственных биотехнологий.

В то же время каждое из упомянутых учреждений проводит независимые исследования и разработки, т.е. не сотрудничает с исследовательскими центрами, находящимися в ведении остальных учреждений, а также самостоятельно занимается коммерциализацией полученных результатов исследований. Данные учреждения создают в рамках инновационной системы Тайваня независимые организации: например, Национальный совет по науке занимается биотехнологиями в рамках Центрального научного парка, Совет по сельскому хозяйству создал на юге Тайваня плантацию орхидей (где разрабатываются новейшие биотехнологии для выращивания этого вида цветов, а продукция плантации активно экспортируется на мировой рынок [13]), 
Министерство экономики сформировало Биотехнологический кластер в Наньгане. С одной стороны, такая борьба интересов обеспечивает диверсификацию исследований и внедрения инноваций, с другой стороны, она приводит к распылению ограниченного количества ресурсов и кадров по разным исследовательским организациям, тем самым снижая общую эффективность инноваций, особенно когда разные организации одновременно работают по схожим проектам.

В других инновационных отраслях на правительство оказывают влияние крупные корпорации и отраслевые объединения. Например, в электронной промышленности это крупные корпорации UMC, TSMC, Acer. Такие отраслевые объединения, как Ассоциация предприятий информационной промышленности, Тайваньская Ассоциация производителей электротоваров и электроники, осуществляют взаимодействие с органами государственной власти, лоббирование политического и экономического курса, благоприятного для предприятий отрасли, участвуют в государственных проектах в области электронной торговли, ориентированных на коммерческий сектор и на малый и средний бизнес $[14,15]$.

Несмотря на значительное ослабление технократов и усложнение процесса принятия решений в области науки и технологий, инновационная система Тайваня продолжила демонстрировать хорошие показатели роста в демократических условиях: в 2010 г. доля расходов на исследования и разработки составила 2,9\% от ВВП, из них 27,5\% были выделены государством, $71,2 \%$ - частными предприятиями, $1 \%$ - учреждениями высшего образования, 0,3\% - частными некоммерческими организациями [16. С. 131-132]. За это время Тайвань достиг впечатляющих результатов в области электронной промышленности и, несмотря на ряд но- вых вызовов, до сих пор остается одним из мировых лидеров в области производства электронной техники, в том числе ноутбуков и мониторов.

Таким образом, в результате политической демократизации процесс разработки и принятия решений в области научно-технологического развития остров претерпел существенные изменения. С конца 1960-х гг. до конца 1980-х гг. основные решения в области развития науки и технологий принимала технократическая верхушка, представленная чиновниками-учеными, которые не имели притязаний на политическую власть (и, отчасти благодаря этому, пользовались доверием высшего руководства Тайваня), принимали решения исходя из своих профессиональных знаний и опыта, и для которых наука и исследования в силу их личных убеждений имели большое значение.

Демократизация авторитарного режима, созданного еще при Чан Кайши, привела к тому, что фактически единоличное руководство экономикой острова, осуществляемое группой технократов, стало невозможным в новых условиях. Демократизация режима, начавшаяся в середине 1980-х гг., обусловила участие более широкого круга лиц в разработке научнотехнологического курса развития. При этом профессиональный уровень лиц, принимающих решения, снизился, а политические интересы стали определяющим фактором в процессе разработки научнотехнологической политики. Более существенное влияние стали оказывать группы интересов (отраслевые объединения предприятий, исследовательские институты и университеты). Вместе с тем повышение самостоятельности научно-технологической системы Тайваня и ее постепенный переход в частный сектор обеспечили повышение ее совокупной эффективности в новых условиях.

\section{ЛИТЕРАТУРА}

1. Wu Yu-Shan. Comparative Economic Transformations: Mainland China, Hungary, the Soviet Union and Taiwan. Stanford University Press, 1994.

2. Ван Цзюнь. Ли Годин: цзишу гуаньляо юй тайваньдэ сяньдайхуа [Ли Годин: технократы и модернизация Тайваня]. Кэсюэ вэньхуа пинлунь. 2009. № 5 [Electronic resource]. URL: http://wenku.baidu.com/view/938d1711fc4ffe473368abf0.html, free (access data: 25.10.2014).

3. Ken Morita, Yun Chen. Transition, Regional Development and Globalization: China and Central Europe. World Scientific Publishing. 2010.

4. Noble G. Incomplete Democratization and Unreconciled Rivalries: Economic Relations Across the Taiwan Strait and Regional cooperation. ISS Comparative Regionalism Project [Electronic resource]. URL: http://project.iss.u-tokyo.ac.jp/crep/pdf/dp/dp6.pdf, free (access data: 25.10.2014).

5. Taiwan Statistical Data Book. Council for Economic Planning and Development, Taiwan. 2005.

6. Ash R., Greene J.M. Taiwan in the 21st Century: Aspects and Limitations of a Development Model. London : Routledge, 2007.

7. Chu Yin-Wah., Wong Siu-Lun. East Asia s New Democracies: Deepening, Reversal, Non-liberal Alternatives. NY : Routledge. 2010.

8. Chou Yang-Sun., Nathan A.J. Democratizing Transition in Taiwan. Asian Survey. 1987. Vol. 27. № 3.

9. Сюй Жэньхуэй. Хэсе шэхуэй юй гунгун чжили [Гармоничное общество и общественное управление]. Чжэцзян дасюэ чжубань, шэхуэй фачжань юй гунгун чжэнцэ сюэшу яньтаохуэй. 2007 [Electronic resource]. URL: http://eppm.shu.edu.tw/file/hsu/b0605.doc, free (access data: 25.10.2014).

10. Chao Chen. Government, governance and innovation policies in small states. Taking Taiwan and Ireland's biotechnology industrial policies for examples (2000-2008). 2008 Doctoral Conference, University of Twente (Netherlands). 2008 [Electronic resource]. URL: http://www.primenoe.org/spip.php?action=acceder_document\&arg=33\&cle=c11ae74ff6337526529589e0e36665fac77d54bf\&file=pdf\%252FChao_Chen.pdf, free (access data: 25.10.2014).

11. White Paper on SMEs in Taiwan 2012. Small and Medium Enterprise Administration, Ministry of Economic Affairs, Taiwan.

12. Lauridsen S.L. State, Institutions and Industrial Development in East Asian NICs. The Copenhagen Journal of Asian Studies. 1993. № 8 [Electronic resource]. URL: http://rauli.cbs.dk/index.php/cjas/article/view/1820, free (access data: 25.10.2014).

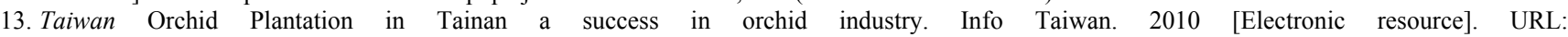
http://www.taiwan.gov.tw/ct.asp?xItem=20908\&ctNode=1940\&mp=999, free (access data: 25.10.2014).

14. Service Scope. Information Service Industry Association, Taiwan. 2012 [Electronic resource]. URL: http://www.cisanet.org.tw/En/ServiceScope, free (access data: 25.10.2014).

15. Domestic business services. Taiwan Electrical and Electronic Manufacturers' Association [Electronic resource]. URL: http://www.teema.org.tw/english/about-teema.aspx? unitid=114, free (access data: 25.10.2014).

16. Taiwan Statistical Data Book 2012. Council for Economic Planning and Development, Taiwan. 


\section{Troynina Ekaterina Y. Tomsk State University (Tomsk, Russian Federation). E-mail: shkrob_katya@mail.ru EVOLUTION OF SCIENCE AND TECHNOLOGY POLICY OF TAIWAN'S GOVERNMENT IN THE 1970-2000S: INTEREST GROUPS.}

Keywords: Taiwan; science and technology; interest groups.

Dynamic science and technology development of Taiwan since 1970-s was entailed by the number of internal and external factors, the main of them, however, was the government policy. Till 1987, while the state of emergency remained valid and under the conditions of authoritarian political regime of Kuomintang, it was Taiwanese technocrats who worked out science and technology policy. The technocrats being loyal to presidents Chiang Kai-Shek and Chiang Ching-Kuo, to some extent were under the ideological influence of the Western science schools, had extensive personal and business relations with the Western, mostly American, businessmen and officials. The technocrats faced little influence from local interest groups as the latter were weak and discrete. Taiwanese technocratic government set up a strong science and technology base, promoted the establishment of state-funded research institutes (ITRI, III) and Hsinchu Science Park, which became the basement for the rapid S\&T development of Taiwan. Political and social changes started in the second half of 1980-s resulted in democratic transition, emergence of legal opposition in 1986 (Democratic Progressive Party) and the transformations of how political decisions were taken. Democratization of Kuomintang regime has led to complication of science and technology policy: on one hand, the competition between various governmental agencies has started, on the other hand, different interested groups gained enough power to put pressure on the government. Taking biotechnology as an example, in 2000-s, under the democratic conditions Taiwan's S\&T policy has been a compromise of the following political powers: 1) executive agencies (National Science Council, Council of Agriculture, Ministry of Health and Welfare, Academia Sinica, etc.); 2) political parties (green coalition under DPP, blue coalition under Kuomintang); 3) business groups: small and medium-sized enterprises as they are the most wide business layer, 4) academics, scientists and experts. Each power strives for promotion of its interests, allocation of resources and subsidies, carries out independent researches in its own realm. The power of the technocrats has eroded in the 2000 -s, and this term is now seldom used to describe politicians in Taiwan. Although democratic transition has undermined the power of technocrats who created science and technology system of Taiwan in 1970-1990-s, by the 2000 the private sector has become mature enough to sustain S\&T development. The quantitative S\&T indicators show that Taiwan S\&T system remained its growth pace and become more private-funded and independent.

\section{REFERENCES}

1. Wu Yu-Shan. Comparative Economic Transformations: Mainland China, Hungary, the Soviet Union and Taiwan. Stanford University Press, 1994.

2. Wang Jun. Li Godin: tszishu guan'lyao yuy tayvan'de syan'daykhua [Lee Godin: technocrats and modernization of Taiwan]. Kesyue ven'khua pinlun', 2009, no. 5. Available from: http://wenku.baidu.com/view/938d1711fc4ffe473368abf0.html. (Accessed: 25th October 2014).

3. Ken Morita, Yun Chen. Transition, Regional Development and Globalization: China and Central Europe. World Scientific Publishing, $2010.506 \mathrm{p}$.

4. Noble G. Incomplete Democratization and Unreconciled Rivalries: Economic Relations Across the Taiwan Strait and Regional cooperation. ISS Comparative Regionalism Project. Available from: http://project.iss.u-tokyo.ac.jp/crep/pdf/dp/dp6.pdf. (Accessed: 25th October 2014).

5. Taiwan Statistical Data Book. Council for Economic Planning and Development, Taiwan. 2005.

6. Ash R., Greene J.M. Taiwan in the 21st Century: Aspects and Limitations of a Development Model. London: Routledge, 2007.304 p.

7. Chu Yin-Wah., Wong Siu-Lun. East Asia s New Democracies: Deepening, Reversal, Non-liberal Alternatives. New York: Routledge, 2010. 328 p.

8. Chou Yang-Sun., Nathan A.J. Democratizing Transition in Taiwan. Asian Survey, 1987, vol. 27, no. 3.

9. Xu Zhenhuey. Khese shekhuey yuy gungun chzhili [Harmonious society and public administration]. In: Chzhetszyan dasyue chzhuban', shekhuey fachzhan' yuy gungun chzhentse syueshu yan'taokhuey. Available from: http://eppm.shu.edu.tw/file/hsu/b0605.doc. (Accessed: 25th October 2014).

10. Chao Chen. [Government, governance and innovation policies in small states. Taking Taiwan and Ireland's biotechnology industrial policies for examples (2000-2008)]. 2008 Doctoral Conference, University of Twente (Netherlands). 2008. Available from: http://www.primenoe.org/spip.php?action=acceder document\&arg=33\&cle=c11ae74ff6337526529589e0e36665fac77d54bf\&file=pdf\%252FChao Chen.pdf. $\quad$ (Accessed: 25th October 2014).

11. White Paper on SMEs in Taiwan 2012. Small and Medium Enterprise Administration, Ministry of Economic Affairs, Taiwan.

12. Lauridsen S.L. State, Institutions and Industrial Development in East Asian NICs. The Copenhagen Journal of Asian Studies, 1993, no. 8. Available from: http://rauli.cbs.dk/index.php/cjas/article/view/1820. (Accessed: 25th October 2014).

13. Taiwan Orchid Plantation in Tainan a success in orchid industry. Info Taiwan. 2010. Available from: http://www.taiwan.gov.tw/ct.asp?xItem=20908\&ctNode=1940\&mp=999. (Accessed: 25th October 2014).

14. Service Scope. Information Service Industry Association, Taiwan. 2012. Available from: http://www.cisanet.org.tw/En/ServiceScope. (Accessed: 25th October 2014).

15. Domestic business services. Taiwan Electrical and Electronic Manufacturers' Association. Available from: http://www.teema.org.tw/english/aboutteema.aspx? unitid=114. (Accessed: 25 th October 2014).

16. Taiwan Statistical Data Book 2012. Council for Economic Planning and Development, Taiwan. 